\title{
Identification and prioritisation of risks in a hospital pharmacy using healthcare failure mode and effect analysis
}

\author{
Maria Ángeles Castro Vida, ${ }^{1}$ Juan Enrique Martínez de la Plata, \\ José Antonio Morales-Molina, ${ }^{1}$ Juan José Pérez Lázaro, ${ }^{2}$ Pedro Acosta Robles ${ }^{1}$
}

\begin{abstract}
- Additional material is published online only. To view please visit the journal online (http://dx.doi.org/ 10.1136/ejhpharm-2017001242).
\end{abstract}

'Department of Pharmacy, Hospital de Poniente de Almeria, El Ejido, Spain ${ }^{2}$ Department of Services and Health Professionals, Escuela Andaluza de Salud Pública, Granada, Spain

\section{Correspondence to} Dr Maria Ángeles Castro Vida, Department of Pharmacy, Hospital de Poniente de Almeria, El Ejido, Andalucía, Spain; mariaangeles.castro@ ephpo.es

JEMP and JAM-M contributed equally.

Received 24 February 2017 Revised 12 August 2017 Accepted 22 August 2017 Published Online First 27 September 2017

EAHP Statement 5: Patient Safety and Quality Assurance.

Check for updates

To cite: Castro Vida MÁ, Martínez de la Plata JE, Morales-Molina JA, et al. Eur I Hosp Pharm 2019:26:66-72.

\section{ABSTRACT \\ Objectives The goals of this project included identifying the processes and subprocesses performed in hospital pharmacies, identifying potential adverse events, detecting failure modes and the causes of errors, prioritising the risks identified and designing a map of risks for hospital pharmacies.}

Methods A task force composed of hospital pharmacy staff was committed to update the diagram of processes and design a map of processes performed in hospital pharmacies. Risks were identified by failure mode and effect analysis annd prioritised according to their risk priority index (RPI) and criticality. A risk map of adverse events was designed based on the diagram of processes and/or primary activities where the prioritised failure modes were most frequent.

Results In total, 99 failure modes associated with 80 adverse events and 129 causes were identified in eight hospital pharmacy areas/subprocesses. The three areas with the highest percentages of failure modes were inpatient pharmaceutical care, pharmacy laboratory and pharmaceutical technology, and medication management. The 25 failure modes (first quartile) with the highest RPI scores (RPI $\geq 20)$ and the 25 failure modes with the highest frequency and criticality scores were classified as priority.

Conclusions According to their RPI, priority failure modes mostly occurred in the area of inpatient pharmaceutical care (92\%). However, according to their criticality, priority failure modes were found to homogeneously occur across all pharmaceutical care areas. As general recommendations pharmacists should assume responsibility and leadership in the implementation of safe medication use practices in healthcare centres.

\section{INTRODUCTION}

The probability of occurrence of adverse events (AEs) in the provision of healthcare services increases with the complexity of the healthcare system and the technologies and processes composing it. Fortunately, healthcare institutions, authorities and organisations-such as the WHOare increasingly concerned about healthcare-associated risks and efforts are being made to promote the implementation of programmes to improve patient safety. $^{12}$

To Err is Human. ${ }^{34}$ The strategic report on patient safety To Err is Human: Building a Safer Health Care System has been crucial to the development of new approaches to improve patient safety at all healthcare levels worldwide.

This document, issued in 2000, reported that 1 million patients got healthcare-associated injuries and 44000-98000 deaths occurred in USA each year as a result of preventable adverse effects, being the eighth cause of mortality in USA. Preventable medical errors cost the USA between $\$ 17$ and $\$ 29$ billion per year.

According to the ENEAS (Estudio Nacional sobre los Efectos Adversos ligados a la hospitalización) study ${ }^{5}$ - a report of AEs related to hospitalisation in Spain-the incidence of patient harm resulting from failures in healthcare processes was $8.4 \%$. As to the severity of injuries, $45 \%$ were mild, $39 \%$ were moderate and $16 \%$ were severe. In total, $37.4 \%$ - of which $42.8 \%$ were considered preventable-of healthcare-related adverse effects were related to medication errors.

The AEs detection is a problem that affects the patient safety and the efficiency of public health system itself, accounting for $1.5 \%$ of Spanish public health expenditure and 3\% of acute hospitals of our environment. ${ }^{6,7}$ The Patient Safety Strategy of the Spanish Healthcare System ${ }^{8}$ - developed within the framework of the National Healthcare Quality Plan-was developed to foster the implementation of safety practices in public healthcare centres. In this strategic plan, the 30 best practices recommended in the National Quality Forum (NFQ)Safe Practices for Better Health Care were turned into indicators for measuring and evaluating healthcare outcomes. ${ }^{9}$ The 2015-2020 patient safety strategy includes an updating of patient safety interventions developed at national and international levels. ${ }^{10} 11$ One of its strategic lines is risk management.

In the healthcare systems of our professional environment (Europe), efforts are being made to improve patient safety. ${ }^{12} 13$ The UK Patient Safety Agency (National Patient Safety Agency) of the National Healthcare System published a reportSeven Steps to Patient Safety-describing the seven steps that national healthcare organisations need to take to improve patient safety. This report has become a reference guide for these organisations, helping them meet their clinical and risk management goals. ${ }^{14}$

The development of effective strategies and practices should be promoted to prevent medication errors in hospitals. The medication delivery system in hospitals is very complex as it consists of numerous components and processes. Measures 
should be taken to prevent medication errors and to raise awareness about them, detect them in a timely manner and prevent that a patient receives the wrong drug.

One of the goals of hospital pharmacy departments is to contribute to the improvement of the health and quality of life of their reference population. Thus, their main objective is to provide effective, safe and efficient drug therapies within the framework of integral and continuous healthcare. Hospital pharmacies should adopt a new approach to promote the safe use of medicines. Thus, as regards the use of medicines, pharmacies should focus on conventional safety practices and on risk management practices.

Identifying and prioritising healthcare-associated risks is an opportunity and a must. Given that healthcare-associated AEs are preventable, a health system needs to implement preventive actions in order to minimise them. The development of risk prevention and reduction measures involves the prior identification of failures in healthcare processes. ${ }^{15}$ Failure mode and effect analysis (FMEA) is an analytical tool recommended by the Institute of Medicine and the Joint Commission on Accreditation of Healthcare Organizations (Standard LD 5.2) as an appropriate procedure to achieve safety in health processes. This tool allows us to prepare the risk map in the care process in order to prevent the failures and analyse the causes and AEs to be able to subsequently develop preventive actions. ${ }^{16} 17$

\section{OBJECTIVES}

1. Identify the processes and subprocesses performed in hospital pharmacies.

2. Identify the AEs that can potentially occur in hospital pharmacies and detect failure modes and causes of errors.

3. Prioritise the risks identified.

4. Design a risk map for hospital pharmacies.

\section{METHODS}

\section{Stage 1: preparation}

A task force was created with the professionals actively involved in the different activities performed in hospital pharmacies. A patient safety monitor was appointed to coordinate the task force and supervise methodological and logistic support. Different pharmacy staff members were included in the task force, namely: hospital pharmacists with experience in different areas, resident hospital pharmacists, a head of unit, and pharmacy technicians involved and familiarised with the activities performed in hospital pharmacies. Task force members met in face sessions and communicated via corporate email. For the development of this project, task force needed four face-to-face workshops of 2 hours. The first session revolved around patient safety and FMEA methodology.

The task force held two meetings to update the diagram of processes that take place in hospital pharmacies and design a map of processes. For this, it was necessary to differentiate between strategic processes, which establish the guidelines to facilitate the adequate results (in general, related to management or leadership); key processes, focused mainly on patients; and support processes, which support key processes, contributing material, organisational and information resources.

a. Identification of strategic processes, support processes and

key processes, and the subprocesses and activities composing them.

b. Updating of the duties and responsibilities of staff members. c. Revision of standard operating procedures (SOP) to document the standardisation of processes.

'Process' was defined as a series of actions or interrelated stages to achieve a goal. 'Procedures' were defined as the documents that detail how a process or activity has to be performed' ${ }^{18}$

\section{Stage 2: identification of risks}

The method selected for the identification of risks was FMEA, a proactive risk assessment tool that is generally used to identify weaknesses in complex, high-risk processes. FMEA facilitates the development of preventive actions that avoid that any harm is inflicted. ${ }^{19}$

For the design of a list of AEs, failure modes and causes, the task force made a presentation on concepts and methods of risk identification in the first session. At last face-to-face workshop, risks were identified by brainstorming. To complete the list, task force members sent their individual contributions to the coordinator via email. The risks identified by task force members were grouped and classified in a table displaying the events, failure modes and causes identified.

Failure prioritisation was performed via email. First, task force members rated the severity and frequency of AEs individually. ${ }^{20}$ The severity and frequency of failure modes were rated on a 1-10 scale taking as a reference assessment scales that convert ORs into scores. ${ }^{1721}$ Mean severity and frequency scores were calculated for each failure mode by the coordinator of expert group.

Next, the mean scores obtained were multiplied together to calculate the risk priority index (RPI). RPI is an FMEA index that includes detectability as a factor. RPI is calculated by multiplying frequency by severity and by detectability $(\mathrm{RPI}=\mathrm{F} \times \mathrm{S} \times \mathrm{D})$. These factors can be converted into a dimensionless numerical code that helps prioritise the corrective interventions to be implemented. This index can be calculated for all types of failure modes. ${ }^{17}$ In our group, detectability was excluded as a variable in order to facilitate the starting up and development of the project. In this way, we calculate prioritisation using frequency and severity as parameters and calculate their product $(\mathrm{F} \times \mathrm{S})$.

Next, the overall results on AEs, failure modes and causes obtained in this stage were sent to task force members.

Finally, failure modes were classified according to their criticality (dichotomous variable: critical or not critical). The addition of criticality was considered as a tool for improving the relevance of the outcomes. To complete the list of priority failure modes, criticality was determined using the FMEA method. ${ }^{22}$ With regard to criticality, when a failure mode was expected to result in a critical AEbe it for the clinical severity of the $\mathrm{AE}$, the substantial economic cost, the loss of prestige suffered by the unit or the high frequency of the AE-the failure mode was considered critical. When criticality is included in the prioritisation, the method is also known as FMEAC.

Priority risks were identified according to their RPI (without detectability) and criticality. The failure modes in which RPI was in the first quartile (an RPI $\geq 20$ ) were analysed. In the same way, the failure modes in the first quartile that were most commonly considered critical were selected.

Following the recommendations of the Clinical Documentation Service of the Reina Sofía University Hospital, Córdoba, Spain — which has broad experience in FMEA-detectability was not included in calculations. Such exclusion was based on the fact that Reina Sofía University Hospital experts compared the RPIs for safety plans obtained by different task forces of the hospital and found that when detectability was excluded from calculations no significant differences arose. ${ }^{23}$ Our workgroup decided to prioritise the failure modes in which RPI and criticality were in the 


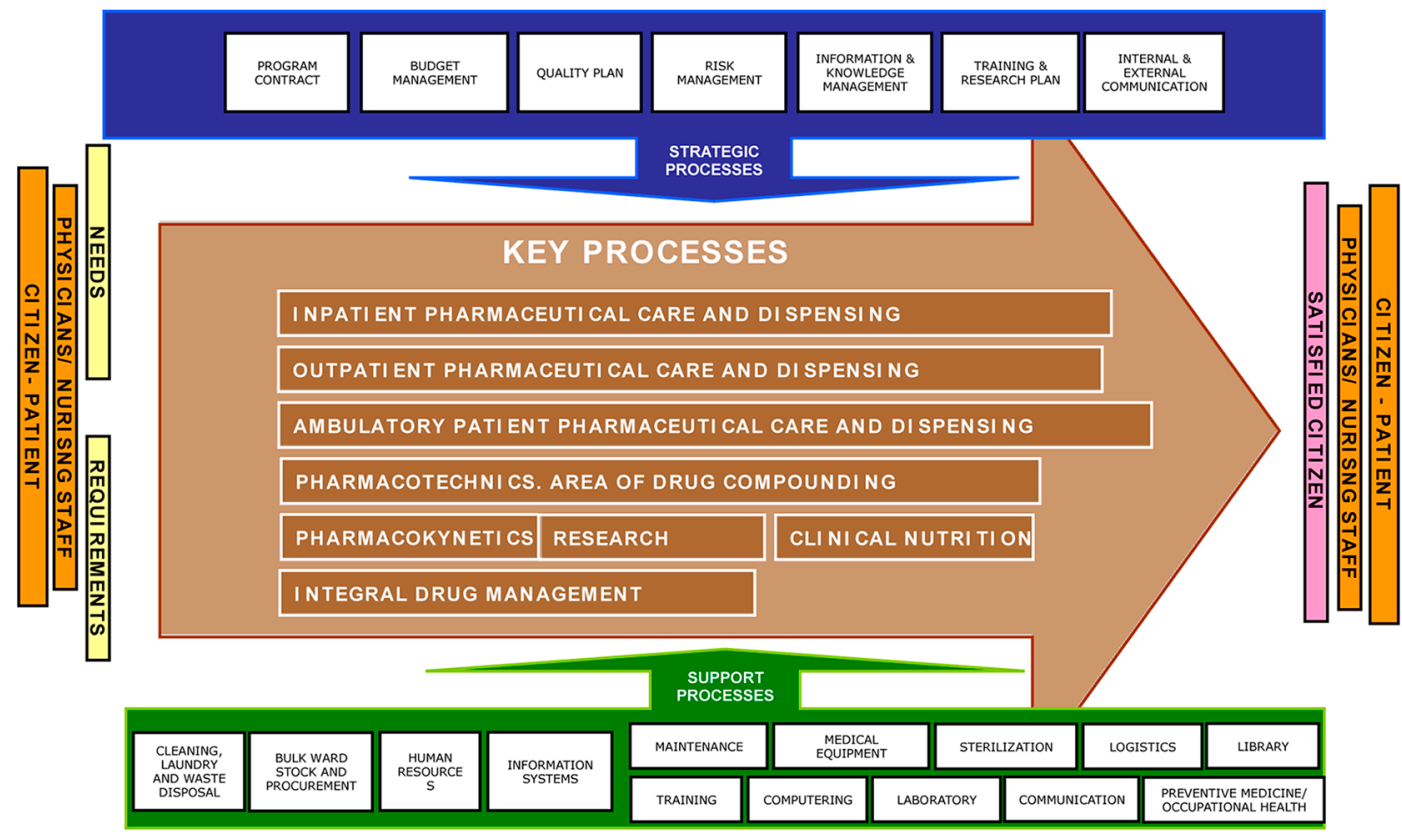

I N A HOSPI TAL PHARMACY

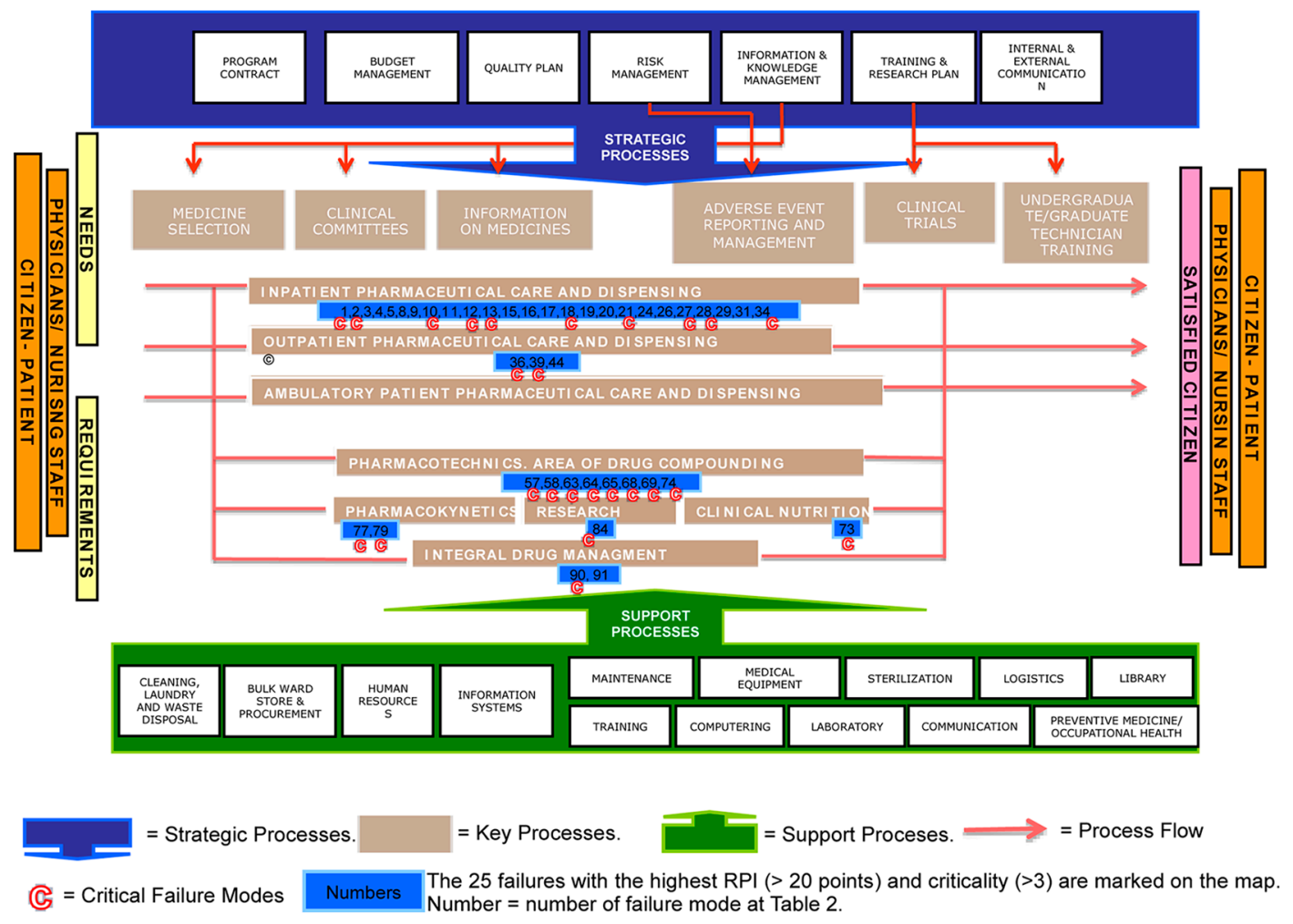

Figure 1 Map of processes in a hospital pharmacy (version 1) and risk map. RPI, risk priority index.

first quartile. A risk map of AEs was designed from the diagram of processes and/or primary activities of prioritised failure modes.

\section{RESULTS}

\section{Diagram of processes}

Strategic processes were identified as follows: contract programme, budget management, risk management, information and knowledge management, education and research plan, internal and external communication.

A total of eight key hospital pharmacy healthcare processes were identified (Figure 1). The duties and responsibilities of hospital pharmacy staff members were defined.

The patients and staff members involved in each process were identified to design the diagram of processes. Following is the list of professionals working in the Hospital of Poniente: 


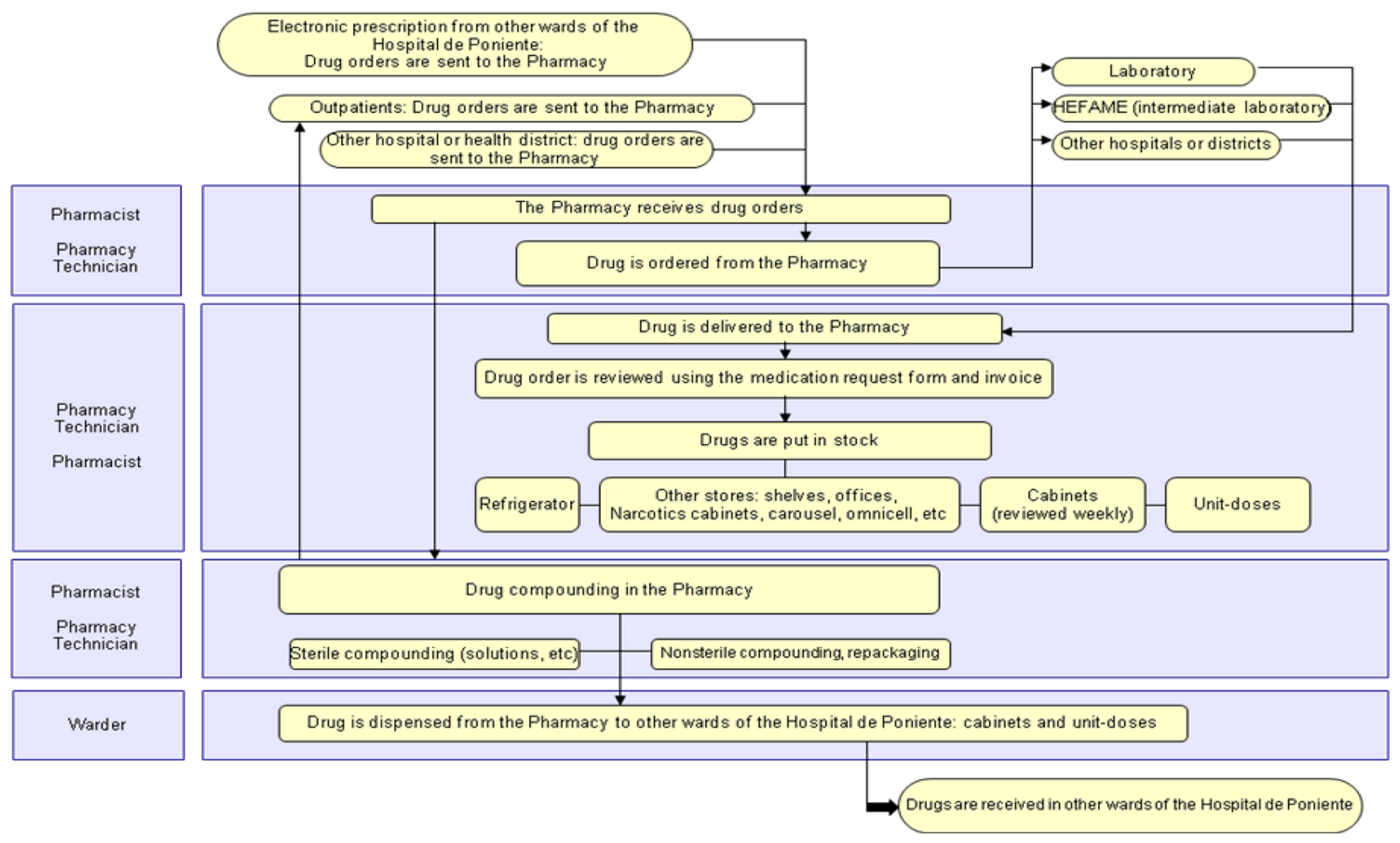

Figure 2 Diagram of hospital pharmacy processes.

specialists from different units, residents, nursing staff, outpatients, inpatients, primary care, ${ }^{24}$ emergency services and the reference hospital.

Based on this information, a draft of the diagram of processes was prepared (figure 1). A diagram of hospital pharmacy processes was also designed (version 2) (figure 2).

\section{Identification of failure modes, AEs and causes}

An eight-area table based on the key hospital pharmacy processes and activities identified was designed for the identification of failure modes, AEs and causes as follows:

1. inpatient pharmaceutical care; unit-dose dispensing system (UDDS)

2. outpatient pharmaceutical care and drug distribution (outpatient unit)

3. pharmacy laboratory and area of pharmaceutical technology

4. area of preparation of intravenous drugs and parenteral nutrition $(\mathrm{PN})$

5. clinical nutrition

6. pharmacokinetics

7. clinical trials

8. medication management.

A total of 99 failure modes associated with 80 AEs and 129 causes were identified. The proportion of failure modes, AEs and causes in the different areas is displayed in table 1.

The three areas with the highest proportion of failure modes were: inpatient pharmaceutical care, pharmacy laboratory and pharmaceutical technology, and medication management. The distribution of percentages for the 80 AEs identified is shown in table 1 . AEs were more frequent in the following three areas: pharmacy laboratory, inpatient pharmaceutical care and outpatient pharmaceutical care.

\section{Prioritisation}

The risk prioritisation index (RPI) was calculated for each of the 99 failure modes identified. A numerical code was correlatively assigned to each failure mode according to their position in the list of failure modes, AEs and causes. This code would be the reference number used in the risk map and for subsequent analysis.

RPI values ranged from 2 to 32 . The 25 failure modes (first quartile) with the highest scores (RPI $\geq 20$ ) were classified as priority failures.

The three failure modes with the highest scores (30 and 32 points) in the area of inpatient pharmaceutical care and UDDS were identified in prioritisation tables (online supplementary table 2) and in the risk map with codes 13, 15 and 16:

- Failure to record patient allergies (AE: administration of a drug to which the patient is allergic: allergic reaction that may cause sensitisation, severe adverse effects or death).

Table 1 Distribution (proportion in percentages) of failure modes, adverse events and causes across the different areas identified during risk identification (respect to total failure modes, adverse events and causes).

\begin{tabular}{|c|c|c|c|}
\hline Area (subprocess) & $\begin{array}{l}\text { Proportion } \\
\text { of failures } \\
(\%)(n=99)\end{array}$ & $\begin{array}{l}\text { Proportion } \\
\text { of AEs (\%) } \\
(n=80)\end{array}$ & $\begin{array}{l}\text { Proportion } \\
\text { of causes (\%) } \\
(n=129)\end{array}$ \\
\hline Inpatient pharmaceutical care. UDDS* & 35.4 & 21.3 & 38.0 \\
\hline $\begin{array}{l}\text { Outpatient pharmaceutical care and } \\
\text { drug dispensing (outpatient unit) }\end{array}$ & 12.1 & 17.5 & 12.4 \\
\hline $\begin{array}{l}\text { Pharmacy laboratory and area of } \\
\text { pharmaceutical technology }\end{array}$ & 17.2 & 23.8 & 17.8 \\
\hline $\begin{array}{l}\text { Intravenous drugs and nutrition (area } \\
\text { of compounding) }\end{array}$ & 3.0 & 1.3 & 6.2 \\
\hline Nutrition & 8.1 & 12.5 & 7.0 \\
\hline Pharmacokinetics & 5.1 & 6.3 & 4.7 \\
\hline Clinical trials & 4.0 & 3.8 & 1.6 \\
\hline Medicine management & 15.2 & 13.8 & 12.4 \\
\hline
\end{tabular}


Proportion of prioritized failures per area (RPI)

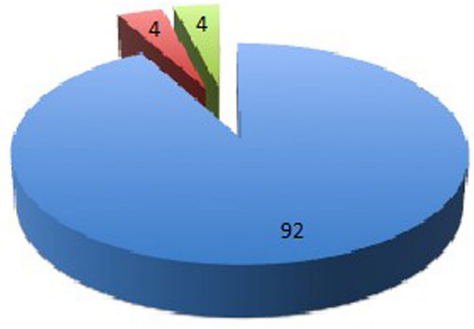

Inpatient Pharmaceutical Care \& Dispensing. UDDS

Ambulatory Patient

Pharmaceutical Care \&

Dispensing (Outpatient Unit)

Medicine Management

\section{Proportion of prioritized CRITICAL failures per area}

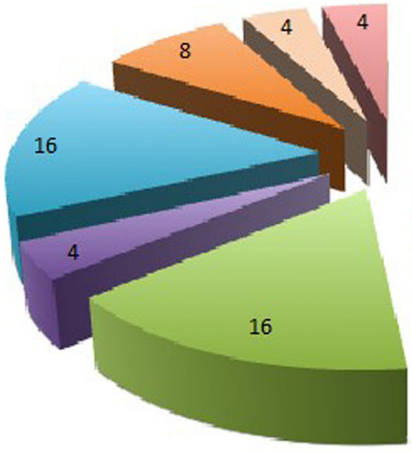

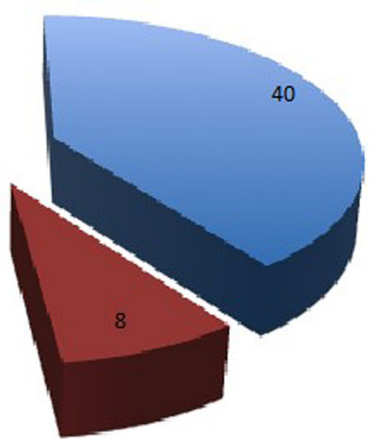

Figure 3 Distribution of priority failure modes (\%) by RPI and distribution of priority failure modes (\%) by criticality. IV, intravenous; RPI, risk priority index; UDDS, unit-dose dispensing system.

Last-minute changes in unit-dose carts (AE: patient receives the wrong medication).

- Drugs are erroneously placed in unit-dose carts (AE: patient receives the wrong drug).

A list of priority critical failure modes was designed (online supplementary table 2). Of the 99 failure modes detected, the 25 failure modes with the highest criticality scores were selected. The three failure modes with the highest scores included (failure modes identified with codes 57, 64 and 68, and marked in dark orange in online supplementary table 2 ):

- Use of the wrong solutes during the preparation of formula or intravenous drugs (AE: the patient receives the wrong formula/intravenous drug).

- Wrong intravenous drug dose (AE: oversdosing, underdosing).

- Wrong preparation of PN/composition error (AE: the macronutrient and micronutrient supply does not comply with the prescribed quantities).

Online supplementary table 2 shows the comprehensive list of risk prioritisation, where failure modes are associated with the potential AEs and causes as identified by RPI and criticality.

According to their RPI, the failure modes to be prioritised occurred in the area of inpatient pharmaceutical care (92\%). However, according to their criticality, priority failure modes were found to homogeneously occur across all pharmaceutical care areas (figure 3 ).

\section{Risk map}

The risks identified are displayed on the map of hospital pharmacy processes with their corresponding codes (figure 1). Failure modes are listed and described in online supplementary table 2. A total of 42 risks were identified, of which 25 were considered critical. Critical risks are marked with a red $\mathrm{C}$ on the map of processes (figure 1).

\section{DISCUSSION}

As stated by Pérez Lázaro et al in their patient safety enhancement plan for pain management units, AEs are actually quality failures with an impact on patient safety. ${ }^{25}$ The ultimate goal of this type of plan is to design a patient safety plan based on the identification, prioritisation and prevention of healthcare-associated risks. ${ }^{26}$

The so-called 'culture of safety' is integrated in routine practice of hospital pharmacists. The culture of safety manifests in different forms in the range of hospital pharmacy activities even with greater intensity than in other hospital units. ${ }^{27}$

The role of hospital pharmacists is crucial to the safe use of medication. Pharmacists must assume responsibility and leadership in the implementation of safe medication use practices in healthcare centres. Hospital pharmacists should identify the risks associated with pharmacy-related processes, implement preventive actions and contribute their experience to other hospital units.

The complexity of hospital pharmacy processes should be considered when designing patient safety plans. Such complexity stems from the centrality of pharmacy services and the heterogeneity of pharmacy staff.

In the patient safety plan designed by the Department of Quality and Clinical Documentation of the Reina Sofía University Hospital, 43 AEs, 65 failure modes and 86 causes were identified. A total of 207 preventive measures were proposed. ${ }^{17}$ Pérez Lázaro et al identified 101 types of failure modes in pain management units that could potentially result in 66 types of AEs induced by 242 causes. $^{26}$ 
Our group identified 99 failure modes associated with 80 AEs and 129 causes in eight hospital pharmacy areas/subprocesses. Pharmacy laboratory and pharmaceutical technology was the area with the highest percentage of AEs. However, the highest percentage of failure modes and causes was identified in the area of inpatient pharmaceutical care and UDDS. According to their RPI, the failure modes to be prioritised occurred in the area of inpatient pharmaceutical care; however, according to their criticality, priority failure modes were found to homogeneously occur across all pharmaceutical care areas. In the same way that Shebl et al concluded, this shows us that you always need a 'gut feeling' prioritisation apart from an FMEA in the strict sense (without criticality). ${ }^{28}$

In the patient safety plan designed by the pharmacy unit of Juan Ramón Jiménez Hospital, Huelva, Spain, 55 specific risks distributed across eight areas of pharmaceutical care were identified. ${ }^{29}$ The results obtained were consistent with those of our study, where 42 risks distributed across 8 pharmacy areas were identified.

On the other hand, in this study, technical and clinical SOPs as well as SOPs related to healthcare equipment have been revised and updated, which is key to the standardisation and improvement of working systems. The continuous updating of procedures-where hospital pharmacists are heavily involved-is key to the harmonisation of criteria, the enhancement of the quality of processes and the improvement of efficacy.

The risk map is useful to determine critical points in terms of patient safety, specifically concerning the safe use of medication in different hospital pharmacy processes. Pharmacy staff can use risk maps to become aware of priority risks and implement preventive measures.

The analysis of the vast volume of data obtained to design a clear and feasible patient safety plan for the area of hospital pharmacy will require a substantial effort.

A limitation of our study is AE duplicity, since some AEs were linked to different failure modes and/or causes, and their grouping in a list was a challenge. Another limitation is that the list of failure modes, AEs and causes is not a comprehensive list, and new AEs and failure modes may be identified in the future thus requiring the development of further prevention. On the other hand, the methodology employed has not been validated, as there are important methodological challenges hindering FMEA validation. ${ }^{29}{ }^{30}$ We focused on priority failure modes, leaving the remaining ones-which could be as, or even more, important-for future analysis. Although many of the failure modes identified can be attributed to physicians, it is the pharmacist who holds the responsibility for confirming and verifying that prescriptions are correct and appropriate to the characteristics of the patient.

\section{CONCLUSIONS}

- The map of processes designed by the task force illustrates complex pharmaceutical care processes in a clear way through the identification of key processes-which guide pharmacy staff work - and support processes - which facilitate pharmacy staff work.

- In our study, a high number of AEs, failure modes and causes were identified. The highest percentage of failure modes and causes was found in inpatient pharmaceutical care and UDDS subprocesses. They were found, in a substantially lower proportion, in the area of laboratory and pharmaceutical technology and in the area of medication management. However, AEs related to them mostly occurred in the area of pharmacy laboratory and pharmaceutical technology.

- The failure modes associated with UDDS and inpatient pharmaceutical care processes are prevalent and the ones with the highest RPI. However, although a high percentage of critical failure modes was found in this area, the distribution of these failsures is homogeneous. Of note is the criticality of potential failures in the area of pharmaceutical technology, the area of aseptic preparation of intravenous drugs and PN solutions.

- The map of processes, together with the identification and prioritisation of failure modes, allowed for the development of a map of risks in hospital pharmacies. This map is a dynamic instrument.

In conclusion, this study served to raise awareness of the importance of patient safety among the personnel involved in pharmaceutical care processes.

\section{What this paper adds}

What is already known on this subject

- Before this project, there were few publications about failure mode and effect analysis (FMEA) method in hospital pharmacy departments. At literature references casts doubt on the usefulness of FMEA as a method in clinical pharmacy.

- It is known that medication errors are one of the leading causes of injury in healthcare system.

- We need to implement risk identification methods in order to prevent adverse events related to drug utilisation.

What this study adds

- FMEA is a useful tool to identify risks and allow us to prioritise those areas and activities in which we can implement improvement actions.

- The results show that there are important differences between the use of FMEA in the restricted sense and adding criticality.

- Commitment of all professionals of the pharmacy department allows to unify criteria and to carry out the same activities within the pharmacy area, which contributes to the improvement of the quality of the processes in which drugs are involved.

Acknowledgements This work belongs in part to the doctoral thesis that one of the authors is developing in the programme of Social Pharmacy at the School of Pharmacy in the University of Granada.

Competing interests None declared.

Provenance and peer review Not commissioned; externally peer reviewed.

(C) European Association of Hospital Pharmacists (unless otherwise stated in the text of the article) 2019. All rights reserved. No commercial use is permitted unless otherwise expressly granted.

\section{REFERENCES}

1 WHO Initial patient safety solutions. http://www.who.int/patientsafety/solutions/ patientsafety/en/ (accessed Jan 2007)

2 Alianza Mundial para la Seguridad del Paciente: Organización mundial de la Salud. http://www.who.int/patientsafety/es/ (accessed Jan 2007).

3 IOM Report on Medical Errors, To Err is Human. National Academy Press, 2000. In: Kohn LT, Corrigan JM, Donaldson MS, To err is human: building a safer health system. Washington DC: National Academy Press, 2000

4 To err is Human - To Delay is Deadly. Ten years later, a million lives lost, billions of dollar wasted. Consumers Union's Safe Patient Project. http://safepatientproject.org/ pdf/safepatientproject.org-to_delay_is_deadly-2009_05.pdf (accessed Jan 2007).

5 Estudio Nacional sobre los Efectos Adversos ligados a la Hospitalización. 2006. ENEAS 2005. Ministerio de Sanidad y Consumo. Madrid: Depósito legal, M. 192002006 . 
6 Bates DW, Spell N, Cullen DJ, et al. The costs of adverse drug events in hospitalized patients. Adverse Drug Events Prevention Study Group. JAMA 1997;277:307-11.

7 Allué N, Chiarello P, Bernal Delgado E, et al. Assessing the economic impact of adverse events in Spanish hospitals by using administrative data. Gac Sanit 2014;28:48-54.

8 Indicadores de buenas prácticas sobre seguridad del paciente. Resultados de su medición en una muestra de hospitales del Sistema Nacional de Salud Español. Madrid: Ministerio de Sanidad y Política Social, 2009.

9 The National Quality Forum. 2003. Safe Practices for Better Healthcare: A Consensus Report. Washington, DC: National Quality Forum. Document NQFCR-05-03.

10 Estrategia de Seguridad del Paciente. Sistema Nacional de Salud. http://www. seguridaddelpaciente.es/resources/documentos/2015/Estrategia\%20Seguridad\% 20del\%20Paciente\%202015-2020.pdf (accessed Jan 2007).

11 Orellana Carrasco R, et al. Gestión de la seguridad del paciente en una Unidad de Urgencias de Atención Primaria. Emergencias 2009;21:415-21.

12 Wang Y, Eldridge N, Metersky ML, et al. National trends in patient safety for four common conditions, 2005-2011. N Engl J Med 2014;370:341-51.

13 Layde PM, Cortes LM, Teret SP, et al. Patient safety efforts should focus on medical injuries. JAMA 2002;287:1993-7.

14 Agencia Nacional para Seguridad del Paciente (NPSA) Sistema Nacional de Salud (NHS), Reino Unido Agencia de Calidad del Sistema Nacional de Salud. La seguridad del paciente en siete pasos: Ministerio de Sanidad y Consumo, 2005. http://www.msssi.gob.es/organizacion/sns/planCalidadSNS/pdf/excelencia/opsc_ sp5.pdf

15 Fernández MT, et al. Diseño e implantación de un plan de seguridad del paciente en un servicio de urgencias de hospital: ¿cómo hacerlo? Emergencias 2013;25:218-27.

16 DeRosier J, Stalhandske E, Bagian JP, et al. Using health care Failure Mode and Effect Analysis: the VA National Center for Patient Safety's prospective risk analysis system. Jt Comm J Qual Improv 2002;28:248-67.

17 Brilli RJ, McClead RE, Crandall WV, et al. A comprehensive patient safety program can significantly reduce preventable harm, associated costs, and hospital mortality. J Pediatr 2013;163:1638-45.

18 "Qué son los procesos asistenciales integrados". Procesos para la Mejora de la Atención Sanitaria. XII Diploma de Especialización en Calidad y Seguridad del Paciente en Instituciones Sanitarias. Granada: Escuela Andaluza de Salud Pública, 2014. Tejedor Fernández, Martín.
19 Ashley L, Armitage G, Neary M, et al. A practical guide to failure mode and effects analysis in health care: making the most of the team and its meetings. Jt Comm J Qual Patient Saf 2010;36:351-8.

20 AMFE. Análisis Modal de Fallos y Efectos. Sinergy: 2008. Análisis Modal de Fallos y Efectos (AMFE). Fundación Iberoamericana para la Gestión de la Calidad Fundibeq. http://www.fundibeq.org/opencms/export/sites/default/PWF/downloads/gallery/ methodology/tools/amfe.pdf (accessed May 2016).

21 Informe Técnico Definitivo. Enero de. Marco Conceptual de la Clasificación Internacional para la Seguridad del Paciente. Versión 1.1: WHO, 2009. http://www. who.int/patientsafety/implementation/icps/icps_full_report_es.pdf.

22 Aguilar-Otero JR, et al. Análisis de modos de fallos, efectos y criticidad (AMFEC) para la planeación del mantenimiento empleando criterios de riesgo y confiabilidad. Tecnol Ciencia Ed 2010:25:15-26.

23 "Seguridad del Paciente", Escuela Andaluza de Salud Pública. 2015. XII Diploma de Especialización en Calidad y Seguridad delPaciente en Instituciones Sanitarias. Granada, Enero: Tejedor Fernández, Martín.

24 Ley de Salud de Andalucía. Ley 2/1998 de 15 de junio. Boletín Oficial de la Junta deAndalucía, no74 (04-07-1998) y Boletín Oficial del Estado, no185, (04-08-1998). https://www.boe.es/diario_boe/txt.php?id=BOE-A-1998-18720 (accessed Jan 2017).

25 Pérez Lázaro JJ, Fernández Ruiz I, Tejedor Fernández M, et al. Identificación y priorización de episodios adversos y fallos relacionados con la seguridad del paciente en las Unidades de Tratamiento del Dolor. Rev Esp Anestesiol Reanim 2012;59:423-9.

26 Pérez Lázaro JJ, Fernández Ruiz I, Tejedor Fernández M, et al. Prevención de eventos adversos para la seguridad del paciente en las unidades de tratamiento del dolor crónico. Rev Esp Anestesiol Reanim 2013;60:204-14.

27 Saturno PJ, Da Silva Gama ZA, De Oliveira-Sousa SL, et al. Análisis de la cultura sobre seguridad del paciente en los hospitales del Sistema Nacional de Salud español. Medicina Clínica 2008;131(Suppl 3):18-25.

28 Shebl NA, Franklin BD, Barber N. Failure mode and effects analysis outputs: are they valid? BMC Health Serv Res 2012;12:150.

29 Sànchez Gómez E, Gonzàlez Rivas y L, Sànchez del Moral R. Elaboración de un plan de seguridad en una unidad de gestión clínica del medicamento. Servicio de Farmacia, Hospital Juan Ramón Jiménez, Huelva, España. Rev Calid Asist 2010;25:223-7.

30 McElroy LM, Khorzad R, Nannicelli AP, et al. Failure mode and effects analysis: a comparison of two common risk prioritisation methods. BMJ Qual Saf 2016;25:329-36. 